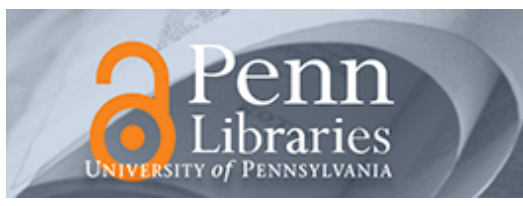

University of Pennsylvania ScholarlyCommons

Wharton Pension Research Council Working

Papers

Wharton Pension Research Council

5-1-2012

\title{
Participating Payout Life Annuities: Lessons from Germany
}

Raimond Maurer

Goethe University, maurer@finance.uni-frankfurt.de

Ralph Rogalla

Goethe University, rogalla@finance.uni-frankfurt.de

Ivonne Siegelin

Goethe University, ivonne.siegelin@hof.uni-frankfurt.de

Follow this and additional works at: https://repository.upenn.edu/prc_papers

Part of the Economics Commons

Maurer, Raimond; Rogalla, Ralph; and Siegelin, Ivonne, "Participating Payout Life Annuities: Lessons from Germany" (2012).

Wharton Pension Research Council Working Papers. 142.

https://repository.upenn.edu/prc_papers/142

This paper is posted at ScholarlyCommons. https://repository.upenn.edu/prc_papers/142

For more information, please contact repository@pobox.upenn.edu. 


\title{
Participating Payout Life Annuities: Lessons from Germany
}

\begin{abstract}
This paper analyzes the regulatory framework of German immediate participating payout life annuities (PLAs), which offer guaranteed minimum benefits as well as participation in insurers' surpluses. Our particular focus lies on the mechanics of sharing surpluses between shareholders and policyholders. We show that the process of surplus determination, allocation, and distribution mostly follows transparent and clear rules, and that an insurance company's management has limited leeway with respect to discretionary decision making. Subsequently, we develop an Asset Liability Model for a German life insurer that offers PLAs. Based on this model, we run Monte Carlo simulations to evaluate benefit variability and insurer stability under stochastic mortality and capital market developments. Our results suggest that through PLAs guaranteed benefits can be provided with high credibility, while, at the same time, annuitants receive attractive Money's Worth Ratios. Moreover, we show that it might be difficult to offer a fixed benefit annuity providing the same lifetime utility as a PLA for the same premium and a comparably low insolvency risk. Overall, participating life annuity schemes may be an efficient way to deal with risk factors that are highly unpredictable and difficult to hedge over the long run, such as systematic mortality and investment risks.
\end{abstract}

\section{Disciplines}

Economics 


\title{
Participating Payout Life Annuities: Lessons from Germany
}

\author{
Raimond Maurer, Ralph Rogalla, and Ivonne Siegelin
}

May 2012

\author{
PRC WP2012-03 \\ Pension Research Council Working Paper \\ Pension Research Council \\ The Wharton School, University of Pennsylvania \\ 3620 Locust Walk, 3000 SH-DH \\ Philadelphia, PA 19104-6302
}

Tel: 215.898.7620 Fax: 215.573.3418

E-mail: prc@wharton.upenn.edu

http://www.pensionresearchcouncil.org

This research reported herein was performed pursuant to a grant from the World Bank. We thank Peter Albrecht, Helmut Gründl, Esko Kivisaari, Olivia S. Mitchell, Heinz Rudolph, Dimitri Vitas, and participants of the World Bank's Fifth Contractual Savings Conference in Washington 2012 for valuable comments. Opinions and errors are solely those of the authors and not of the institutions with whom the authors are affiliated. (c) 2012 Maurer, Rogalla, and Siegelin. 


\begin{abstract}
$\underline{\text { Abstract }}$
This paper analyzes the regulatory framework of German immediate participating payout life annuities (PLAs), which offer guaranteed minimum benefits as well as participation in insurers' surpluses. Our particular focus lies on the mechanics of sharing surpluses between shareholders and policyholders. We show that the process of surplus determination, allocation, and distribution mostly follows transparent and clear rules, and that an insurance company's management has limited leeway with respect to discretionary decision making. Subsequently, we develop an Asset Liability Model for a German life insurer that offers PLAs. Based on this model, we run Monte Carlo simulations to evaluate benefit variability and insurer stability under stochastic mortality and capital market developments. Our results suggest that through PLAs guaranteed benefits can be provided with high credibility, while, at the same time, annuitants receive attractive Money’s Worth Ratios. Moreover, we show that it might be difficult to offer a fixed benefit annuity providing the same lifetime utility as a PLA for the same premium and a comparably low insolvency risk. Overall, participating life annuity schemes may be an efficient way to deal with risk factors that are highly unpredictable and difficult to hedge over the long run, such as systematic mortality and investment risks.
\end{abstract}

Raimond Maurer (corresponding author)

Finance Department, Goethe University

Grueneburgplatz 1 (Uni-PF. H 23)

Frankfurt am Main, Germany

e-mail: maurer@finance.uni-frankfurt.de

\title{
Ralph Rogalla
}

Finance Department, Goethe University

Grueneburgplatz 1 (Uni-PF. H 23)

Frankfurt am Main, Germany

Email: rogalla@finance.uni-frankfurt.de

\section{Ivonne Siegelin}

Finance Department, Goethe University

Grueneburgplatz 1 (Uni-PF. H 23)

Frankfurt am Main, Germany

Email: Ivonne.Siegelin@hof.uni-frankfurt.de 


\title{
Participating Payout Life Annuities: Lessons from Germany
}

\author{
Raimond Maurer, Ralph Rogalla, and Ivonne Siegelin
}

\section{Introduction}

Reaching retirement raises the question how to draw down assets that individuals have accumulated during their working lives. A traditional vehicle is to purchase life annuities sold by insurance companies or pension funds. In exchange for a non-refundable premium, typically paid as a lump-sum at the date of purchase, the insurance company promises to make a series of periodic payments to the annuitant given his or her survival. As Mitchell/Poterba/Warshawsky/Brown (1999) point out the main characteristic of life annuities is that they protect annuitants against the risk of outliving accumulated savings in retirement by pooling longevity risk across a group of annuity purchasers. In general, annuity payments may be fixed in nominal terms (fixed annuity), rising at a pre-specified fixed nominal escalation rate (grade annuity) or be indexed to inflation (real annuity). Payments may also reflect the return of a specific asset portfolio that backs the annuity (investment-linked annuity) or depend on the insurance company's overall experience regarding mortality, investments, and expenses (participating annuity).

Recent work by Horneff/Maurer/Mitchell/Stamos (2009, 2010), Maurer/Somova (2009), and policy work developed at the World Bank by Vittas (2010), Vittas/Rudolph/Pollner (2010), and Rocha/Vittas/Rudolph (2011) studied the regulatory framework of fixed and investment-linked payout annuities. Yet, very little is known on participating annuities, which are the focus of this paper and the standard product in the German market (see Kaschützke/Maurer 2011). Typically, participating life annuities offer guaranteed minimum benefits for the remaining lifetime and an additional nonguaranteed surplus. The guaranteed benefits are calculated using conservative actuarial assumptions on investment return, mortality, and costs. Therefore life insurance companies can expect to earn a systematic surplus. A large proportion of the surplus generated by the insurance company has to be shared with and distributed to policyholders, whereby the mechanics of surplus allocation are regulated by the supervising authority. A distinguishing feature of participating annuities is that, once distributed, surpluses can be incorporated into the guaranteed benefits.

As pointed out by Albrecht/Maurer (2002) insurance companies are using special smoothing techniques to attempt stable surplus rates over time. Besides distributing surpluses at a stable rate, providers also try to maintain the real value of benefits after inflation. Hence, participating annuities could be a promising annuity type for pension schemes in countries that cannot provide inflationlinked annuities or are not able to offer investment-linked payout annuities. Recent work by Kartashov/Maurer/Mitchell/Rogalla (2011) shows that sharing systematic longevity risk between annuitants and annuity providers can effectively be implemented by using participating annuities. 
This article makes an effort to understand the basic features of the participating life annuity products in the contemporary German life insurance market. ${ }^{1}$ We will discuss the process of surplus determination, the different return sources, the transparency and the regulatory framework of sharing surpluses between shareholders and policyholders. The paper will also explore the smoothing mechanism that is used to stabilize the surplus distribution. Finally an asset and liability model of an annuity provider with uncertain investment returns and mortality developments is designed. This model allows us to study the risk and return profile of the annuitant's payout stream as well as the risk exposure of the insurance company.

\section{Participating Life Annuities}

\subsection{General Characteristics}

The payout stream of German participating life annuities (PLAs) consists of two parts: guaranteed benefits and distributed surpluses. Guaranteed benefits have to be paid for the remaining lifetime of the annuitant. Hence, they have to be calculated "on the safe side" (see § 11 Insurance Supervision Act, VAG) to ensure the long-term ability of insurers to honor the obligations from contracts. To this end, calculation of premiums and reserves for guaranteed lifetime benefits is based on so-called first order actuarial assumptions. The first order actuarial assumptions are specified when the contract is signed and cannot be changed during the lifetime of the annuitant. The main parameters are low guaranteed interest rates, conservative mortality tables and prudent cost rates.

Since premiums are calculated in a conservative way, life insurance companies can expect to earn a systematic surplus. The basis for calculating surpluses is the difference between first and second order actuarial assumptions. The second order assumptions are determined by the insurer at the end of every financial year, and depend on the insurers' experiences on investments, mortality, costs, and other sources like re-insurance. As surpluses result not only from the entrepreneurial and management skills of an annuity provider, but to a substantial amount from the legally prescribed prudent calculation, insurance companies are obliged to share every source of return with the policyholders (see $§ 153$ VAG). Sharing profits with the annuitants means paying an unguaranteed amount in addition to the guaranteed benefits.

Usually annuities are offered by life insurance companies as a part of their overall product portfolio. Other important product lines include term life insurance and endowment policies. Changes in the second order actuarial assumptions have different impact on the return of each product line. A reduction of the actual life expectancy, for example, increases mortality returns for annuity products,

\footnotetext{
${ }^{1}$ Life insurance is the largest sector in the German private insurance market with earned premiums of $156.1 \mathrm{bn}$ Euro in 2009 and total reserves of about 30\% of the German GDP. Within the life insurance business annuity products have a market share of about $20 \%$.
} 
but lowers mortality returns for pure life products. To share profits fairly and to prevent uncontrolled cross subsidies, surpluses have to be calculated separately for each product groups. Furthermore, the set of policies per product has to be split into subsets or so-called profit series with matching first order assumptions and surpluses have to be calculated for each profit series.

When signing the contract, the annuitant can choose between two participation schemes: Surplus annuitization and lump-sum surplus distribution. If the policyholder chooses the former, surpluses are annuitized based on the same actuarial assumptions that were used to calculate premiums. In this case, the annuitized surpluses raise benefits and also become part of the guaranteed benefits in subsequent years. If the lump-sum option is chosen, the annuitant receives surpluses year by year as one-time payments that do not become part of the guaranteed benefits.

Due to adverse selection issues, annuitants do not have the option to cancel their contract and receive a repurchase value, even if this option is given for other German life insurance products, such as endowment policies. Therefore, the insurers have to inform potential annuitants about the actuarial assumptions used before signing the contract. Moreover, they have to illustrate future benefit developments depending on realistic assumptions on surpluses. ${ }^{2}$

To protect guaranteed payments promised to annuitants, life insurance companies are subject to a comprehensive regulatory framework codified in the Insurance Supervision Act and supervised by the German Federal Financial Supervisory Authority (BaFin). Besides solvency requirements and building sufficient actuarial reserves, life insurance companies also have to account for quantitative restrictions on their investments (e.g. maximum exposure to equities, real estate and alternative investments). In addition there are two institutions to protect the insured in case of insolvency: Protektor Lebensversicherungs AG, a privately organized institution with voluntary membership, and the mandatory solvency fund for life insurers organized by the government. Finally, each life insurance company has to appoint a responsible actuary. The responsible actuary supervises the calculation of premiums and reserves for guaranteed benefits and is also involved in supervising the determination, allocation, and distribution of surpluses to policyholders.

\subsection{PLA Return Sources}

Based on data provided by the BaFin, Table 1 presents aggregated surpluses of all German life insurers from 2007 to 2009, itemized by return sources. Legislation stipulates that insurers have to determine and distribute surpluses from mortality, assets and costs as well as the performance in re-

\footnotetext{
${ }^{2}$ The insurance contract act (VVG) regulates the minimum amount of information that PLA providers must give to annuitants: type of contract, premium, costs, guaranteed pension, and projections of future benefits developments including surpluses.
} 
insuring and other sources. The two main sources of return are assets and mortality. In the years, 2007 to 2009, insurers have taken annual profits of more than 6,000 million Euros from mortality, a number than has been rather stable over time. Asset returns, on the other hand, exhibit high volatility. In 2007, asset returns contributed $62 \%$ of overall surpluses. This number decreased to only $13 \%$ in 2008 , and increased again to $54.7 \%$ in 2009.

Cost returns are generated due to safety margins calculated for acquisitions of new contracts and running expenses. Other returns include profits produced by re-insurance and premium reduction. Table 1 shows that cost and other returns are low compared to asset and mortality returns.

\section{Table 1 here}

The most important source of surplus, asset return is calculated as the difference between net investment returns and guaranteed interest. The net investment return contains earned coupon payments from fixed income investments, dividends from stocks and rents from property investments. Gains and losses due to sale, acquisition or new valuation of assets are also included. As shown in Figure 1, asset surpluses are generated because the guaranteed interest rate (GIR) is significantly below the net investment returns. The maximum GIR annuity providers can choose is defined in the premium refund order ( $§ 2$ DeckRV). It is set by German ministry of finance and usually amounts to $60 \%$ of the average yield of government securities during the last ten years. As illustrated in Figure 1, the GIR decreased successively since 1994, from 4\% to 2.25\%. From January 2012 on, the maximum GIR will be reduced again to $1.75 \%$.

\section{Figure 1 here}

Given that insurance companies in every year have to earn at least the guaranteed interest, their investment policies favor allocation to bonds. As shown in Table 2, 66.5\% of the assets over all German life insurers in 2010 are bonds and less than 1\% of the assets are directly invested in stocks. The second largest asset class is investment funds, with the main part of these funds being fixed income funds. For example, Allianz AG, the biggest German life insurer, reported that $88 \%$ of the investment funds held in 2011 were bond funds and only the remaining 12\% were equity funds. Overall, approximately $90 \%$ of insurers' assets are allocated to bonds.

\section{Table 2 here}

Besides profits generated through the asset allocation, mortality return is also an important source of surplus. It is calculated as the difference of expected and actual mortality reserve. The actual mortality is observed by the insurer at the end of every financial year. Expected mortality, by contrast, is taken from the mortality table used to calculate the annuity premium. For pricing annuities, German life 
insurers currently apply mortality tables recommended by the German Association of Actuaries (DAV), called "DAV 2004 R”. These dynamic life tables are available since 2004 and depend on gender, age and year of birth. Prior to that, life tables called "DAV 1994 R" were used, which only considered age and gender. Almost all insurers calculate premiums based on the DAV mortality tables. Only the biggest German insurance company, Allianz AG, develops its own mortality tables for calculating private annuities, as only their portfolio of policies is large enough to support viable mortality estimates. Unisex products and therefore unisex mortality tables also exist in Germany, but they are not commonly used for PLAs at the moment.

For men born in 1946, Figure 2 presents annuitants' mortality rates well as actual population mortalities. The former are based on the "DAV 2004 R" table and the corresponding trend adjustment factors provided by DAV. The latter are based on a period mortality table provided by the Human Mortality Database, which we transform into a cohort table by projecting future mortality rates using a Lee/Carter model. The figure illustrates that the deviation of mortality assumptions used for pricing PLAs from actual mortalities results in systematic mortality returns.

Figure 2 here

A summary measure often used by actuaries and demographers to express the differences between two mortality tables is the A/E-ratio. Formally it is defined as:

$$
\frac{A}{E}=\frac{\sum_{x=1}^{\omega} w_{x} q_{x}^{I}}{\sum_{x=1}^{\omega} w_{x} q_{x}^{I I}} \cdot 100
$$

As pointed by McCarthy/Mitchell (2010) this measure is equivalent to a weighted average of mortality rates for the two life tables, with weights equal to the remaining population under the benchmark table. A value of 100 implies that the average mortality structure is equal for the two tables; while a value of less than 100 means that the average mortality in the benchmark table is lower. In our case, $\mathrm{q}_{\mathrm{x}}^{\mathrm{I}}$ represents the probability of an $\mathrm{x}$ year old male to die within the next year according to annuitants table "DAV 2004 R". In turn, $q_{x}^{I I}$ is the probability of an x year old German male to die within the next year according to the population table provided by the Human Mortality Database. For the weights $\mathrm{w}_{\mathbf{x}}$ we set the initial population at age $x=1$ to 100,000 . Subsequently weight evolve according to $\mathrm{w}_{\mathrm{x}+1}=\mathrm{w}_{\mathrm{x}}\left(1-\mathrm{q}_{\mathrm{x}}^{\mathrm{I}}\right)$, i.e. the benchmark is the annuitant table. The terminal age of the mortality table is given by $\omega$, which is 100 for the population and 120 for the annuitant mortality table. A comparison between the annuitant specific mortality table "DAV 2004 R" and the population table used here results in an $\mathrm{A} / \mathrm{E}$ ratio of approximately 60 . This is a relatively low value, meaning that the annuitant table assumes a mortality structure which on average is about $40 \%$ lower than the population table. 


\subsection{Mechanics of Surplus Determination, Allocation, and Distribution}

Estimation of profits as well as the share for distribution to policyholder is regulated in a special directive issued by the German financial supervision authority (BaFin). The process of determination, allocation and distribution of surplus is summarized in Figure 3. A life insurance company's overall surplus first has to be determined by policy category, e.g. annuities, term life insurance, or other available insurance lines. Then, surpluses determined for each policy category have to be broken down by profit series, itemized by source of return. A profit series within a specified policy category is the portfolio of contracts that have equal first order actuarial assumptions. In the next step, the determined surplus has to be allocated among policyholders and shareholders according to pre-specified sharing rules. Finally, the allocated surplus has to be distributed among policyholders. Typically, allocated surpluses are not fully paid out to policyholders in any given year, but are partially stored in a special reserve fund. This enables the insurer smooth surplus payouts to policyholders over time.

Figure 3 here

Surplus Determination: Surpluses are determined on a single contract basis according to the contribution formula in Equation 1 (see Wolfsdorf 1997). The profits $g_{x, t}$ of an x year old male in the t-th year of the contract can be broken down into mortality return $g_{x, t, q}$, asset return $g_{x, t, i}$ and cost return $g_{x, t, K}$.

$$
g_{x, t}=g_{x, t, q}+g_{x, t, i}+g_{x, t, K}
$$

Mortality return $g_{x, t, q}$ is the deviation between actual mortality $q_{x+t}^{I I}$ and expected mortality $q_{x+t}^{I}$ multiplied by actuarial reserve ${ }_{t+1} V_{x}$. Hence, mortality returns become positive if mortality observed at the end of the financial year is higher than that used in calculating the PLA.

$$
g_{x, t, q}={ }_{t+1} V_{x}\left(q_{x+t}^{I I}-q_{x+t}^{I}\right)
$$

Asset return $g_{x, t, i}$ is the actuarial reserve of the previous year ${ }_{t} V_{x}$ less guaranteed annuity payments $L_{t}^{x}$, running expenses $\sigma_{t}$, and other costs $\gamma_{t} S$ multiplied by the difference of actual net investment return $i_{t}^{I I}$ and GIR $i_{t}^{I}$.

$$
g_{x, t, i}=\left({ }_{t} V_{x}-L_{t}^{x}-\gamma_{t}^{I} S-\sigma_{t}^{I}\right)\left(i_{t}^{I I}-i_{t}^{I}\right)
$$


Cost return $g_{x, t, K}$ is the difference between the expected and the actual costs for managing an insurance contract compounded with the actual interest rate.

$$
g_{x, t, K}=\left(\left(\gamma_{t}^{I}-\gamma_{t}^{I I}\right) S+\left(\sigma_{t}^{I}-\sigma_{t}^{I I}\right)\right)\left(1+i_{t}^{I I}\right)
$$

Surplus Allocation: Policyholders have to participate in every source of return. The minimum amount that has to be shared with the annuitants according to the Minimum Profit Sharing Act (MindZV) is at least $90 \%$ of asset returns, at least $75 \%$ of mortality returns, and at least $50 \%$ of other return sources. Annuitants can only participate in positive return categories and cross-charging between categories is prohibited. Therefore, any negative return from each category directly reduces the equity capital of the insurance company.

While the percentages mentioned above are minimum requirements, it is customary in particular trade that more than $90 \%$ of surpluses over all sources of return are allocated to the policyholders. Based on data provided by BaFin, Table 3 shows actual surplus allocations from 2005 to 2009, aggregated over all German life insurers. Over this period, $92 \%$ of all surpluses have been allocated to the policyholders on average.

\section{Table 3 here}

Not only policyholders, but also shareholders have to participate in the profits of an insurance company. The share of profits allocated to the shareholders has to be at least $4 \%$ of the authorised equity capital (§65 VAG). This minimum requirement, however, has no economic relevance, as authorised equity capital is only a fraction of the stock price.

Surplus allocation and distribution have to be approved by management board, taking into account the recommendation of the responsible actuary. The supervisory authority monitors that the minimum surplus distribution requirements are met and it has the right to intervene in case of inappropriate surplus distribution to annuitants. Finally, the insurer has to disclose detailed information about participation rates in the annual report.

Surplus Distribution and Smoothing: The annuity provider can distribute the allocated surplus among three accounts: uncommitted provision for premium refunds (uncommitted PPR), committed provision for premium refunds (committed PPR), or direct deposits. The PPR positions are special items in the life insurer's balance sheet and play a key role in distributing and smoothing surpluses. Their sum is the second largest item on the liabilities side of the balance sheet, exceeded only by the actuarial reserve. Surpluses to be paid to the beneficiaries within the next two years are assigned to the 
committed PPR. Within the committed PPR account, assigned distributed surpluses are recorded on a single contact basis. The uncommitted PPR is a collective buffer account belonging to all insured that is used to smooth fluctuations of the distributed surpluses over time. Here, the insurer can set aside reserves in good times and withdraw them when needed. Surpluses to be paid to the beneficiaries immediately are assigned to the direct deposits.

Committed PPR, as well as direct deposits, are tied reserves to which policyholders have legal claim. Hence, these reserves require Solvency Capital. Funds in the uncommitted PPR, on the other hand, are untied reserves that do not require Solvency Capital. Consequently, the insurer is interested in a wellfilled uncommitted PPR account. Allocated surpluses, however, cannot be assigned to the uncommitted PPR arbitrarily. On the one hand, the regulator stipulates that the sum of committed and uncommitted PPR is limited to the sum of all allocations into the PPR over the three previous years. Hence, the uncommitted PPR is indirectly limited. On the other hand, annuity providers do business in a competitive market environment, where the level of surplus distributed to annuitants is the dominating factor by which potential clients measure the performance of an insurer.

As mentioned before, annuitants can choose between two participation schemes: surplus annuitization and surplus lump-sum. Choosing one or the other does not only affect the annuitant's payout stream, it also affects the insurer's reserves. Paying a surplus lump-sum directly reduces the insurer's cash position. Annuitizing distributed surpluses leaves the cash position unchanged but raises the actuarial reserve.

\subsection{Historical Distributed Surpluses and Implied Benefit Variations}

Drawing on data taken from the Assecurata Surplus Sharing Studies for the years 2004 to 2010, Figure 4 illustrates the range of distributed surpluses in the German life insurance industry, presenting averages as well as the 5\% and 95\% quantiles. Here, distributed surplus is defined as the increase of the annuity benefits as a percentage of the actuarial reserve. Panel 1 depicts distributed surpluses for the profit series based on a guaranteed interest rate (GIR) of 4\% and mortality from the "DAV 1994 R" table, Panel 2 those for the profit series based on a GIR of $2.75 \%$ and the "DAV 2004 R" table. The former profit series represents a market environment in the mid 1990, when guaranteed interest rates were high and mortality rates were less conservative than today. By contrast, the second profit series corresponds to a more current market situation with both lower guaranteed interest and mortality rates. Naturally, the resulting guaranteed benefits in Panel 1 have to be higher than those in Panel 2.

Figure 4 here 
The level of distributed surpluses strongly depends on the actuarial assumptions underlying the respective profit series. While average distributed surpluses for the product with high guaranteed benefits in Panel 1 only amount to $0.25 \%$ p.a., those with lower guaranteed benefits in Panel 2 come to more than $1.5 \%$ p.a. Looking at the $5 \%$ and $95 \%$ quantile of the range of surplus as well as their fluctuation over time, it can be seen that the insurance industry as a whole was able to maintain rather stable distributed surpluses within each profit series.

The annuitants' payout profile does not only depend on the level of distributed surplus but also on the surplus payout option chosen. In order to illustrate the impact of assigned profit series and chosen payout policy on the payout profile over time, let us assume that in 2003 four PLAs were purchased, each for a premium of $100 €$. The surplus payout option for PLA-1 and PLA-2 was annuitization, for PLA-3 and PLA-4 lump-sum payout. PLA-1 and PLA-3 were calculated using a GIR of $4.00 \%$ and mortality "DAV 1994 R" (initial pension: 7.47€), whereas the calculation of PLA-2 and PLA-4 was based on a GIR of $2.75 \%$ and mortality "DAV 2004 R" (initial pension: 6.13€). Figure 5 presents the distributional evolution of total benefits paid by each of the four (hypothetical) PLAs over the period 2003 to 2010, based on the range of distributed surpluses presented in Figure 4. In case of surplus annuitization, benefits increase every year by the percentage of the average distributed surplus. The benefits of PLA-2 increase faster than those of PLA-1, but even in the best case PLA-2 does not reach the initial pension of PLA-1.

In case of PLA-3 and PLA-4, the value of the surplus lump-sum is determined as the distributed surplus percentage times the actuarial reserve. Every year, this value is added to the initial pension. In 2004 the benefit payments to annuitants are similar for both contracts. As the lump-sum value is based on the actuarial reserve, the spread between the $5 \%$ and the $95 \%$ quantiles in both graphs becomes thinner over the years.

Figure 5 here

\section{Modelling PLA Payouts and Insurer Stability under Investment and Longevity Risk}

After having discussed the key characteristics determining German PLAs, we now investigate whether the parameters stipulated by regulation and/or adopted by the insurance industry result in sustainable guaranteed pensions, distributed surpluses, and company stability. To this end, we develop a stochastic asset and liability model for a stylized German life insurance company that sells only one product, a single-premium PLA, to a specific cohort of equal individuals that are exposed to capital market and longevity risks.

\subsection{Model and Calibration}




\subsubsection{Capital Market Model}

The portfolio of our life insurance company contains two assets, stocks and bonds. The stochastic dynamics of bond prices are determined based on a Cox-Ingersoll-Ross (CIR) model. The CIR model assumes that the short rate, $r_{t}^{C I R}$, satisfies

$$
d r_{t}^{C I R}=\alpha\left(\mu^{C I R}-r_{t}^{C I R}\right) d_{t}+\sigma^{C I R} \sqrt{r_{t}^{C I R}} d W_{t}^{1}, r_{0}^{C I R}>0,
$$

where $\alpha$ and $\mu^{C I R}$ are positive scalars, $\sigma^{C I R}$ the volatility parameter and $W_{t}^{1}$ is a standard Wiener process. The market price for zero bonds at time $t$ with a cash flow of one monetary unit at maturity in time $T$, i.e. the discount factors implied in the spot rate curve, can be calculated analytically according to

$$
Z_{t}^{T}=E_{t}^{Q}\left[e^{-\int_{t}^{T} r_{s}^{C I R} d s}\right]=\exp \left(\mathrm{A}(T-t)-\mathrm{B}(T-t) r_{t}^{C I R}\right),
$$

where the parameters $\mathrm{A}$ and $\mathrm{B}$ are defined as

$$
\begin{gathered}
\mathrm{A}(\theta)=\frac{2 \alpha \mu^{C I R}}{\left(\sigma^{C I R}\right)^{2}} \log \left[\frac{2 \gamma e^{(\gamma+\alpha) \theta / 2}}{(\gamma+\alpha)\left(e^{\gamma \theta}-1\right)+2 \gamma}\right] \\
\mathrm{B}(\theta)=\frac{2\left(e^{\gamma \theta}-1\right)}{(\gamma+\alpha)\left(e^{\gamma \theta}-1\right)+2 \gamma} \\
\gamma=\sqrt{\alpha+2\left(\sigma^{C I R}\right)^{2}} .
\end{gathered}
$$

At time $t$ the price of the coupon paying bond $B_{t}^{T}$, with a constant coupon rate $C^{T}$, a face value of $N$, and a maturity at $T$ is given according to

$$
B_{t}^{T}=N\left[\sum_{i=t+1}^{T} C^{T} Z_{t}^{i}+Z_{t}^{T}\right]
$$

where $Z_{t}^{i}$ are the discount factors from the current term structure generated by the CIR model (Equation 6). In each year, the company at least has to earn the GIR and is, therefore, interested in a stable income steam from bonds. Consequently, we assume that the company only invests in coupon paying par bonds with fixed initial maturity $T$. With $B_{0}^{T}=B_{T}^{T}=N$ at purchase time $t$, the par yield is given by

$$
C^{T}=\frac{1-Z_{t}^{T}}{\sum_{i=t+1}^{T} Z_{t}^{i}}
$$


Stock prices and dividend payments are modelled separately as we are interested in the annual payments of the assets. The level of stock price $S_{t}$ is described by the following stochastic process:

$$
S_{t}=S_{t-1} \cdot e^{r_{t}^{C I R}+r_{t}^{R P}}=S_{t-1} \cdot e^{r_{t}^{C I R}+\mu^{R P}+\sigma^{R P} W_{t}^{2}}
$$

where $r_{t}^{C I R}$ is the short rate of the CIR model and $r_{t}^{R P}=\mu^{R P}+\sigma^{R P} W_{t}^{2}$ is the risk premium, $\mu^{R P}$ and $\sigma^{R P}$ are constants and $W_{t}^{2}$ is a standard Wiener process. Bonds and stocks are correlated because the short rates $r_{t}^{C I R}$ are used to model the stock prices. Dividend payments $D_{t}$ are presumed to evolve according to:

$$
D_{t}=S_{t-1} \cdot\left(e^{\mu^{D}}-1\right)
$$

where $\mu^{D}$ is a constant.

Based on historical spot rates of Federal Securities with 10 year maturity over the period 1988-2011 provided by the Deutsche Bundesbank, we calibrate the CIR model using the martingale approach by Bibby/Sørensen (1995). Hence, we posit a long term mean $\left(\mu^{C I R}\right)$ of $3.46 \%$, a speed of adjustment factor $(\alpha)$ of 0.07472 , and a volatility parameter $\left(\sigma^{C I R}\right)$ of $2.96 \%$. Our initial spot rate $r_{0}^{C I R}$ is set to $1.5 \%$. The development of the stock prices and dividend rates is calibrated based on DAX Total Return Index and DAX Price Index over the same period as the spot rates. This results in the following estimates: the expected risk premium $\left(\mu^{R P}\right)$ is equal to $0.2 \%$, the volatility parameter $\left(\sigma^{R P}\right)$ is equal to $25 \%$, and the fixed dividend $\left(\mu^{D}\right)$ is $2.3 \%$. The asset allocation of bonds and stocks follows a constant mix strategy. The portfolio of the insurance company is rebalanced annually toward the targeted allocation when assets are sold to pay benefits to the annuitants. In case the stock exposure exceeds the target weight, for example, the insurance company sells a higher percentage of stocks to pay the benefits.

\subsubsection{Mortality Model}

The mortality rates $q_{x, c}^{I I}$ for age $x$ and calendar year $c$ are forecasted using a Lee Carter (LC) model which is denoted as follows:

$$
\log q_{x, c}^{I I}=a_{x}+b_{x} k_{c}+\varepsilon_{x, c}
$$

The model Lee/Carter proposed in 1992 is driven by a single time-varying component $k_{c}$. The age specific parameter $a_{x}$ indicates the average level of $\log q_{x, c}^{I I} ; b_{x}$ is another age specific parameter 
characterizing the sensitivity of $\log q_{x, c}^{I I}$ and $\varepsilon_{x, c}$ is the error term capturing the remaining variations. To estimate future mortality rates, the time dependent component $k_{c}$ is forecasted using a random walk with drift:

$$
k_{c}=k_{c-1}+\mu^{L C}+\varepsilon_{c}
$$

where $\mu^{L C}$ is the drift of $k_{c}$ and $\varepsilon_{c}$ is normally distributed $\left(\varepsilon_{c} \sim N\left(0, \sigma^{L C}\right)\right)$. In the following, $q_{x, c}^{I I}$ will be denoted as $q_{x}^{I I}$. We assume in our company model an initial cohort of individuals,

$$
N I_{0}=\sum_{i=1}^{n} x_{0, i}=n
$$

with

$$
{ }_{x} I_{0, i}=1 \text {, for } i=1, \ldots, n
$$

The number of individuals, $N I_{t}$, at time $t$ is calculated using

$$
N I_{t}=\sum_{i=1}^{n}{ }_{x} I_{t, i}
$$

For each individual $i$ the sequence of binomial random variables ${ }_{x} I_{t, i}$ forms a Markov Chain with

$$
\begin{gathered}
P\left({ }_{x} I_{t+1, i}=\left.1\right|_{x} I_{t, i}=1\right)=1-q_{x+t}^{I I}=p_{x+t}^{I I}, \\
P\left({ }_{x} I_{t+1, i}=\left.0\right|_{x} I_{t, i}=1\right)=q_{x+t}^{I I}, \\
P\left({ }_{x} I_{t+1, i}=\left.0\right|_{x} I_{t, i}=0\right)=1 .
\end{gathered}
$$

To forecast the mortality rates $\log q_{x, c}^{I I}$ we calibrate the LC model on German mortality data from the Human Mortality Database. We estimate a drift for the random walk $\left(\mu^{L C}\right)$ of -2.87 , an average mortality level $\left(a_{65}\right)$ at age 65 of -3.9 , and a sensitivity $\left(b_{65}\right)$ of 0.01 . In our model all individuals ${ }_{x} I_{t, i}$ have the same age and gender; they purchase the annuity in the same year with matching first order actuarial assumptions. The number of individuals $n$ is set to 10,000 .

\subsubsection{Company Model}


In order to distribute surpluses to the policyholders we first have to calculate the companies' profits (surplus determination). Subsequently, surpluses are allocated to policyholders and shareholders. Finally, to smooth the annual surplus payout, surpluses are distributed to the committed and uncommitted PPR. In our company model, we only account for asset and mortality returns and do not include costs. In this case, the contribution formula (1) to determine the profits in year $k$ reduces to

$$
g_{x, k}=g_{x, k, q}+g_{x, k, i},
$$

where the mortality return $g_{x, k, q}$ is given by

$$
g_{x, k, q}={ }_{k+1} V_{x}\left(q_{x+k}^{I I}-q_{x+k}^{I}\right)
$$

with actuarial reserve ${ }_{k+1} V_{x}$, actual mortality $q_{x+k}^{I I}$ forecasted by the LC model and expected mortality $q_{x+k}^{I}$ taken from mortality tables "DAV $2004 \mathrm{R}$ ”. Asset return $g_{x, k, i}$ is given by

$$
g_{x_{i}, k, i}=\left({ }_{k} V_{x}-L_{k}^{x}\right)\left(i_{k}^{I I}-i_{k}^{I}\right)
$$

Here, $L_{k}^{x}$ are the payments to the annuitant, $i_{k}^{I}$ is the GIR used to price the annuity and $i_{k}^{I I}$ is the realized net investment return of the bond-stock portfolio. The net investment return is calculated as the sum of all dividend payments, coupon payments, and realized gains/losses due to sale of assets. This sum is divided by the book value of invested assets at the beginning of the year.

$$
i_{k}^{I I}=\frac{\alpha_{S, k} D_{k}+\alpha_{B, k} C^{T}(k)+\beta_{S, k}\left(S_{k}-S_{0}\right)+\beta_{B, k}\left(B_{k}^{T}-N\right)}{\alpha_{S, k} S_{0}+\alpha_{B, k} N}
$$

In the upper formula, $\alpha_{S, k}\left(\alpha_{B, k}\right)$ is the number of stocks (bonds) held in year $k$ and $D_{k}\left(C^{T}(k)\right)$ is the dividend (coupon) payment for each stock (bond). $\beta_{S, k}$ denotes the number of stocks sold at market price $S_{k}$ resulting in a realized gain or loss with respect to the purchase price $S_{0}$ of $\beta_{S, k}\left(S_{k}-S_{0}\right)$. The realized gain or loss from selling $\beta_{B, k}$ units of bonds at market price $B_{k}^{T}$ relative to a book value of $N$ is given by $\beta_{B, k}\left(B_{k}^{T}-N\right)$. In case the company holds stocks/bonds with different book values, assets are sold according to the FIFO rule.

Aggregating over all contracts, the profits of the insurance company, $U E_{k}$, can be determined by 


$$
U E_{k}=\sum_{i=1}^{n} g_{x, k}(i)
$$

Next, profits have to be allocated to policyholders and shareholders, taking into account the regulatory minimum requirements presented in Figure 3 in Section 2.3. Policyholders are eligible to at least $75 \%$ of positive mortality returns and $90 \%$ of positive asset returns, while they do not participate in negative returns. To facilitate the calibration of our model to market data, we allow the company to allocate a fixed percentage $a p$ of total surpluses to policyholders, in case this amount exceeds the regulatory minimum. To prevent insurer insolvency due to excessive distribution of surplus, we postulate that an additional management rule governs the determination of allocated surpluses: ap $\%$ of the profits are allocated to the policyholders as long as the insurer's equity capital is above $50 \%$ of the initial equity capital. In case equity drops to below $50 \%$ of its initial value, only the regulatory minimum of surplus is allocated to policyholders. Therefore, the total allocated surplus $A S_{k}$ to policyholders is calculated as follows

$$
A S_{k}= \begin{cases}\sum_{i=1}^{n} \max \left[0.75 \cdot \max \left(g_{x, k, q}(i), 0\right)+0.9 \cdot \max \left(g_{x, k, i}(i), 0\right), a p \cdot g_{x, k}(i)\right], E_{k}>0.5 E_{0} \\ \sum_{i=1}^{n}\left[0.75 \cdot \max \left(g_{x, k, q}(i), 0\right)+0.9 \cdot \max \left(g_{x, k, i}(i), 0\right)\right], & E_{k} \leq 0.5 E_{0} .\end{cases}
$$

The remaining profits are distributed to shareholders. Hence, the equity capital $E_{k}$ develops according to

$$
E_{k+1}=E_{k}+U E_{k}-A S_{k}
$$

In the next step, the allocated surplus is distributed to committed and uncommitted PPR. The target value for the uncommitted PPR is a pre-specified percentage of the actuarial reserve. As long as the uncommitted PPR is below this level, a portion of $A S_{k}$ is allocated here. When the uncommitted PPR is above the target value, excess funds are transferred to the committed PPR.

In order to model a viable insurance company, we have to make several assumptions regarding the initial liability side of the company's balance sheet. On average, German insurers' equity amounts to about $1.5 \%$ of the balance sheet total. Hence, we adopt this number for our model company. As it is common for German insurance companies to distribute surpluses to the policyholders already in the first year, we initially endow the committed PPR with $1 \%$ of the actuarial reserve. Moreover, we set 
the initial uncommitted PPR, which acts as a buffer stock against adverse capital market and mortality developments, to $2 \%$ of the actuarial reserve. The remainder of the balance sheet total is made up by the actuarial reserve, which consists of the premiums collected from the cohort of initially 10,000 annuitants.

Surpluses are appropriated to the PPR such that distributed surpluses may not increase by more than $25 \%$ or decrease by more than $20 \%$ compared to last year's distributed surpluses. At the same time, the targeted value of the uncommitted PPR is $4 \%$ of the actuarial reserve.

Finally, shareholders receive an annual dividend amounting to $2.3 \%$ of the current equity capital at the end of the financial year, which is in line with empirically observable dividend yields.

\subsubsection{Money's Worth Ratio and Utility-Equivalent Fixed Life Annuity}

To determine the value that PLAs are delivering to the annuitant, we will apply the money's worth methodology used by Mitchell/Poterba/Warshawsky/Brown (1999). Our goal is to use this value to make this special German product comparable across countries and product structures. The money's worth ratio $(M W R)$ is calculated as the present value of PLA payouts relative to the annuity premium $P$ payed when the contract is signed:

$$
\text { MWR }=\sum_{k=1}^{\omega-(x+1)} \frac{{ }_{k} p_{x}^{I I} L_{k}^{x}}{\prod_{i=0}^{k-1}\left(1+E\left(f_{i, i+1}\right)\right)} \frac{1}{P}
$$

Here, ${ }_{k} p_{x}^{I I}$ is the probability of an $x$-year old male to survive the next $k$ years with ${ }_{k} p_{x}^{I I}=1-{ }_{k} q_{x}^{I I}$ and ${ }_{k} q_{x}^{I I}$ forecasted by the LC model. $L_{k}^{x}$ is the (uncertain) payout of the annuitant in year $k$ and $\omega$ is the terminal age of the mortality table. The premium the annuitant has to pay to the insurance company is calculated using according to the actuarial equivalence principle:

$$
P=R \cdot \sum_{k=0}^{\omega-(x+1)} \frac{k{ }_{k}^{I}}{(1+G I R)^{k}}
$$

where $q_{x}^{I}, \quad\left(p_{x}^{I}=\left(1-q_{x}^{I}\right)\right)$ is the mortality for age $x$ and calendar year $c$ under first-order actuarial assumptions, GIR the guaranteed interest rate, and $R$ the annually guaranteed annuity benefit. Explicit costs in terms of loading are not considered. In our case, we receive a path of uncertain annuity benefit payments $L_{k}^{x}$ for each simulation of our company model. All payments on each path are discounted using the expected one period forward rates $\mathrm{E}\left(f_{i, i+1}\right)$, which are generated by the CIR model. Following 
this approach, we estimate a MWR for each simulated path and, hence, we generate a distribution of MWR.

Following Mitchell/Poterba/Warshawsky/Brown (1999), with a $M W R$ of 1, the annuitant can expect one euro in today's terms for every euro he invested in the annuity. A $M W R$ of less than 1 implies that the premium charged by the insurance company exceeds the present value of the PLA. $M W R<1$ is common, but it does not mean that a rational annuitant would not buy this annuity. In Mitchell/Poterba/Warshawsky/Brown (1999) individuals without a bequest motive would still prefer buying an annuity with a $M W R$ of 0.8 over following an optimal consumption and investment strategy.

In addition to the MWR, we determine the value of PLAs for annuitants with differing personal discount rates and risk aversion parameters. To this end, we calculate the utility-equivalent fixed annuity for annuitants with a time additive CRRA utility function. The expected lifetime utility is given by

$$
U=E\left(\sum_{k=1}^{\omega-(x+1)} \beta^{t-1}{ }_{k}^{I I} \frac{L_{k}^{x(1-\gamma)}}{1-\gamma}\right)
$$

Here, $\gamma$ denotes the coefficient of relative risk aversion, the discount factor $\beta<1$ represents the individuals' subjective time preference. The expected life-time utility $U$ is transformed into a utilityequivalent fixed annuity $E A$ and is defined as follows

$$
E A=\left[\frac{U(1-\gamma)}{\sum_{k=1}^{\omega-x+1} \beta_{k}^{t-1} p_{x}^{I I}}\right]^{\frac{1}{(1-\gamma)}}
$$

The EA can be interpreted as the constant guaranteed lifelong income stream the annuitant requires to give up the upside potential of a PLA with uncertain surpluses.

\subsection{Base Case Simulation Results}

In this section, we evaluate benefit payout streams as well as insurance company stability implied by the model designed above. To this end, we simulate 50,000 independent sample paths for a cohort of 10,000 males aged 65 in 2012 that purchase a PLA with initial guaranteed pension benefits of 10,000€ per year. Insurance premiums are calculated using a guaranteed interest rate of $1.75 \%$ per year and the annuitant specific mortality tables "DAV 2004 R". By contrast, the simulated mortality dynamics of our annuitant pool are governed by a LC-model that we calibrate to overall population mortality data. 
The asymmetric mortality assumptions in our model setup imply systematic mortality returns in expectation. To focus the analysis on the impact of the various participation schemes, we abstract from expense loadings. The fixed asset allocation is a 10/90-percent stock/bond mix, with bonds having an initial maturity of 10 years. The surplus allocation parameter, which specifies the distribution of profits between annuitants and shareholders, is set to $a p=92 \%$. In the base case scenario the distributed surpluses are used to raise the annual pension (surplus annuitization). In sensitivity analyses we also explore the effects of distributing surpluses as lump-sum payments.

Figure 6 presents the annual distributed surplus to a representative annuitant in percent of the actuarial reserve from age 65 to age 95 for both participation schemes, surplus annuitization (Panel A) and surplus lump-sum (Panel B). To visualize the uncertainty of the annual pension as well as the development of the insurance company's equity capital, we present the distribution of these parameters using fancharts.

Over the first three years, the level of the distributed surplus comes to about $1 \%$ for both payout schemes (Panels A1 and B1). This surplus level was initially set in our company model. Over the first years, the uncommitted PPR has to be built up to the targeted level, which has priority over paying out additional surpluses to annuitants.

After the uncommitted PPR has been filled, average distributed surplus increases to about 2\% p.a., where it remains until age 75. At age 76, we can observe a systematic rise in the distributed surplus level in both panels. At the same time, the overall range of distributed surpluses becomes wider. This increase is caused by the underlying CIR model in conjunction with the maturity of bonds. The initial short rate is only $1.5 \%$, which results in a yearly coupon only $1.85 \%$ for a par bond with 10 years maturity. After 10 years, the principal of the bonds becomes payable and has to be reinvested. By that time, the interest rate level has increased significantly in expectation, as the long run mean in the CIR model is $3.46 \%$. Consequently, newly purchased bonds pay a higher coupon rate. From age 85, the distributed surplus for the base case setting has an upward trend, while it is downward trending in the lump-sum scenario. This difference in the development of distributed surpluses for the two payout options can be explained as follows. In case surpluses are annuitized, cash outflows to annuitants in excess of the guaranteed pension are low early in retirement (see Panel A2). At the same time, accumulated surpluses increase the actuarial reserve and, hence, more surplus-generating assets are kept in the insurance company. By contrast, under the lump-sum distribution scheme, surpluses are paid out immediately (see Panel B2), which over time reduces the company's potential to generate additional surpluses. 
Besides looking at the development of annuity benefits, it is of interest to study the viability of the annuity provider. With PLAs, insurers provide guarantees to the annuitants. Hence, the latter might be concerned that the insurer will not be able to maintain the guarantee due to insolvency. Looking at Panels A3 and B3 of Figure 6, we see that the insurer's equity capital will not be exhausted, even in the worst cases. Hence, insolvency risk is negligible. At the same time, we find that average equity capital not even doubles over the 30 year horizon under investigation. This addresses a second major concern annuitants might have: does the insurer keep too much of surpluses generated. The increase in equity corresponds to an annual growth rate of less than $2 \%$ per year in addition to the $2.3 \%$ annual dividend payments. This indicates that the insurer does not unduly withhold surpluses from the annuitants.

Figure 6 here

Finally, Figure 7 compares the spectrum of MWR's for the base case and the lump-sum scenario. The medium MWR of 0.94 for the base case scenario is slightly below the MWR of 0.95 in the lump-sum payout scenario. Such MWR below unity are caused by the delayed payout of surpluses and not by high return on equity for the PLA providers. In the base case scenario, the spread between the upper and lower whisker of the MWR is marginally wider. Hence, if the annuitant chooses the surplus annuitization option, the upside potential of pension benefits is slightly higher than in case surpluses are paid as lump-sums. Yet, comparing the 5\%-quantiles, the enhanced upside goes along with lower benefits in case of a less favorable capital market and longevity environment.

It should be noted that cost loadings, charged by the PLA provider to cover expenses for acquisition and management, are not included in the analysis. Such expenses increase annuity premiums and reduce MWRs. For immediate PLAs, the German Insurance Association (see GDV 2011) reports average costs of $6.6 \%$ on top of the actuarial fair annuity premium (acquisition costs $5.2 \%$, costs of management 1.4\%). Considering expense loadings our base case scenario reduces expected MWR from $95 \%$ to $89 \%$, on average. This value is in line with the average MWR based on empirical annuity quotes for the German market reported in Kaschützke/Maurer (2011).

Figure 7 here

\subsection{Sensitivity Analysis}

We now study the robustness of our results with respect to the variation of central parameters. In particular, we vary bond fraction and maturity as well as the level of surplus allocation to the policyholders. Our findings are summarized in Table 4, which presents the development of average distributed surpluses over time for alternative calibrations. 


\section{Table 4 here}

The average distributed surplus rises with the stock fraction. Especially at high ages the distribution of surpluses to the policyholder increases substantially. An increasing stock fraction, however, results in higher risk exposure for the annuitants, as the company's ruin probability rises accordingly. While in the base case/no stocks case none of our 50,000 simulation runs resulted in negative insurer equity, in the maximum stock fraction scenario $11 \%$ of our simulations led to negative equity in at least one period.

When comparing the base case with the short maturity scenario, we find an alternating pattern in average distributed surpluses. At ages 70, 80, and 90, average distributed surpluses in the base case exceed those in the short maturity case. At ages 75 and 85, this relation is reversed. In our calibration, the initial interest rate level is well below the long-term mean. At the same time, the term structure is normal, i.e. interest rates increase with maturity. Consequently, the yield of short-term bonds is below that of bonds with longer maturity, and so are the surpluses generated. Short-term bond investments, however, have to be rolled-over already by age 70. By that time, the interest level has - on average already increased toward the long-term mean, and the newly purchased short-term bonds yield more than the initial long-term bond. Hence, at age 75 , surpluses under the short maturity scenario exceed those of the base case. With interest rates converging to the long-term mean, the impact of the term structure being normal on average starts to dominate, and surpluses in the base case scenario continuously exceed those in the short-term maturity scenario.

In case the insurer decides to only distribute the regulatory minimum to policyholders, distributed surplus falls short of that in the base case scenario by around $10 \%$ in the early 70 s and by more than $20 \%$ in the mid 90s. Yet, even in this case, policyholders benefit substantially from generated surpluses.

Finally, we are interested in whether our modeling of PLAs results in systematic gender biases. To get an indication, Figure 8 presents the distribution of the MWRs for males and females for both surplus annuitization as well as lump-sum payout. The average MWRs for females are slightly but not disproportionally higher than for males, as are the dispersions. As presented in Figure 6 as well as in Table 4, the distributed surplus at high ages increases disproportionally. With a higher life expectancy, the number of females reaching these advanced ages exceeds that of males and, hence, women benefit more from this effect. 


\subsection{Utility Analysis}

Finally, we analyze the utility that annuitants draw from PLAs with alternative payout schemes as well as asset and surplus allocation rules. To this end, we transform the simulated PLA payout streams into a utility-equivalent fixed life annuity by inverting a time-additive CRRA utility function (Equation 27). Table 5 presents the results for alternative rates of time preference and risk aversion. In what follows, we classify those annuitants with a coefficient of relative risk aversion of $\gamma=2 / 5 / 10$ as low/medium/high risk averse. Correspondently, those with subjective discount factor of $\beta=$ 0.98/0.96/0.94 as patient/normal/impatient individuals.

\section{Table 5 here}

In the base case scenario, the equivalent fixed life annuity for patient annuitants with a low risk aversion is $12,080 €$. The utility drawn from PLAs decreases with increasing risk aversion and impatience. For a highly risk averse but patient individual, the PLA generates the same utility as a fixed annuity paying 11,530€ for life. The PLA's utility for an impatient annuitant with low risk aversion, on the other hand, would only equal a fixed annuity of $11,120 €$. Naturally, individuals with higher risk aversion dislike the inherent volatility in PLA benefits. At the same time, with a GIR of $1.75 \%$, the guaranteed minimum return on the PLA falls short of the personal discount rate of even the patient annuitants. Hence, all scenarios show the same pattern. Independent of risk aversion and impatience, PLAs with lump-sum surplus distribution, scenario, generate higher utility for the annuitant than those with surplus annuitization. Equivalent fixed life annuities range from $12,420 €$ for a patient individual with low risk aversion to $11,890 €$ for a highly risk averse impatient annuitant.

To put these numbers into perspective and relate them to the (stylized) market situation adopted in our model, we conduct the following experiment. Let us assume that a life insurance company offers a fix (non-participating) life annuity of $12,080 €$ per annum, i.e. the utility-equivalent annuity for a patient individual with low risk aversion. To be able to offer such an annuity for the same premium as the PLA, the insurer, when relying on the same mortality table, has to calculate the fixed annuity with an interest rate of $3.63 \%$. This is $1.88 \%$ higher than the GIR of $1.75 \%$ used in calculating the PLA. Since the initial coupon rate for long term bonds is only $1.85 \%$, guaranteeing an interest of $3.63 \%$ results in substantial insolvency risk.

To quantify this risk, we redo our simulation for a cohort of 10,000 individuals that purchase a guaranteed fixed annuity of 12,080€ instead of a PLA with an initially guaranteed 10,000€ plus surplus participation, relying on the same assumptions about the stochastic dynamic and initial parameters of capital market, individual and systematic longevity developments, and asset allocation. 
We then evaluate how many of our 50,000 simulations lead to negative equity capital in at least one year, i.e. in how many cases the insurer becomes insolvent. We find this number to be $48.1 \%$. By contrast, in case the insurer offers a PLA that provides the same lifetime utility, the probability of insurer insolvency is $0 \%$. These results suggest that, for our (stylized) market situation, insurers will face substantial difficulties to offer a fixed life annuity for the same premium as a PLA, which at the same time provides comparable insolvency risk and lifetime utility.

\section{Discussion and Conclusions}

This paper analyzes participating payout life annuities (PLAs), which are the dominating product in the German market. Participating life annuities offer relatively low guaranteed lifetime benefits in combination with access to parts of the surplus generated by the insurer. In contrast to traditional life annuities with fixed benefits, PLA pension payments can fluctuate over time. At the same time, the surplus does not depend on the performance of a specific asset portfolio chosen by the annuitant, as e.g. in the case of an investment-linked variable payout annuity, but it depends on the insurance company's overall experience regarding mortality and investments. Another distinct feature of German PLAs is that it is possible to annuitize distributed surpluses and, hence, increase guaranteed benefits.

Keys questions when implementing PLAs are how surpluses are determined and allocated among policyholders and shareholders. We show that in Germany the process of surplus determination, allocation, and distribution mostly follows transparent and clear rules, and that an insurance company's management has limited leeway with respect to discretionary decision making. This process is strictly monitored by the responsible actuaries and the financial supervisory authority. Yet, despite its transparency, the mechanics are complex and no easily understandable even for financially literate individuals.

Our analysis of the German market shows also that insurance companies try to smooth surplus distribution over time. To this end, insurers have two instruments at hand. First, investment returns on assets held by the insurance companies are determined on the basis of book rather than market values. Second, surpluses are not fully distributed to the individual policyholders in the year they are generated but averaged over time, using a special buffer fund.

From our simulation analysis we learn that insurance companies offering PLAs based on the German regulatory framework are able to provide guaranteed minimum benefits with high credibility. This is due to the fact that minimum benefits are calculated using conservative assumptions regarding mortality experience and investment performance. At the same time, simulated Money's Worth Ratios come to around 95\%, on average. This indicates that annuity providers cannot unduly take advantage 
of the conservative assumptions, as the participation scheme provides a way to transfer realized profits back to the policyholders.

In a further analysis, we study the utility provided by PLAs for individuals with different levels of risk aversion and impatience. Our calculations suggest that it might be difficult to offer a fixed benefit annuity providing the same lifetime utility as a PLA for the same premium and a comparably low insolvency risk.

Overall, participating life annuity schemes may be an efficient way to deal with risk factors that are highly unpredictable and difficult to hedge over the long run, such as systematic mortality and investment risks. 


\section{References}

Albrecht, Peter and Raimond Maurer (2002): Self-Annuitization, Consumption Shortfall in Retirement, and Asset Allocation: The Annuity Benchmark, Journal of Pension Economics \& Finance 1, 269-288.

Assecurata (Ed.) (2004): Marktstudie 2004: Die Überschussbeteiligung in der Lebensversicherung, Köln 2004, Download at: www.assekurata.de/.

Assecurata (Ed.) (2005): Marktstudie 2005: Die Überschussbeteiligung in der Lebensversicherung, Köln 2005, Download at: www.assekurata.de/.

Assecurata (Ed.) (2007): Marktstudie 2007: Die Überschussbeteiligung in der Lebensversicherung, Köln 2007, Download at: www.assekurata.de/.

Assecurata (Ed.) (2009): Marktstudie 2009: Die Überschussbeteiligung in der Lebensversicherung, Köln 2009, Download at: www.assekurata.de/.

Assekurata, (2009), Überschussbeteiligung 2009: Die Gewinnbeteiligung der Versicherten in Zeiten der Kapitalmarktkrise.

Bibby, B.M., M. Sørensen (1995): Martingale estimating functions for discretely observed diffusion processes, Bernoulli 1, 17-39.

Bundesanstalt für Finanzdienstleistungsaufsicht (2011), Jahresbericht 2010 der Bundesanstalt für Finanzdienstleistungsaufsicht.

GDV (2011) (Gesamtverband der Deutschen Versicherungswirtschaft): Die deutsche Lebensversicherung in Zahlen, Geschäftsentwicklung 2010, Berlin 2011.

Horneff, W.; R. Maurer, O. S. Mitchell, \& M. Stamos (2010): Variable Payout Annuities and Dynamic Portfolio Choice in Retirement, Journal of Pension Economics and Finance 9, 163-183.

Horneff, W.; R. Maurer, O. S. Mitchell, \& M. Stamos (2009): Asset Allocation and Location over the Life Cycle with Survival-Contingent Payouts, Journal of Banking and Finance 33, 1688-1699.

Kartashov, V., R. Maurer, O.S. Mitchell, \& R. Rogalla (2011): Lifecycle Portfolio Choice with Systematic Longevity Risk and Variable Investment-Linked Deferred Annuities, NBER Working Paper 17505.

Kaschützke, Barbara and Raimond Maurer (2011): The Private Life Annuity Market in Germany: Products and Money’s Worth Ratios, in: O.S. Mitchell, J. Piggott, and N. Takayama (Ed.), Securing Lifelong Retirement Income, Global Annuity Markets and Policy, New York 2011.

Maurer, Raimond and Barbara Somova (2009): Rethinking Retirement Income Strategies: How can we Secure better Outcomes for Future Retirees? Brussels.

McCarthy, David and Olivia S. Mitchell (2010): International Adverse Selection in Life Insurance and Annuities, International Studies in Population 8, 119-135.

Mindestzuführungsverordnung vom 4. April 2008 (BGBl. I S. 690). 
Mitchell Olivia S., James Poterba, Mark Warshawsky, and Jeffrey R. Brown (1999): New Evidence on the Money’s Worth of Individual Annuities, American Economic Review 89,1299-1318.

Rocha, Roberto, Dimitri Vittas, and Heinz Rudolph (2011): Annuities and Other Retirement Products: Designing the Payout Phase. The World Bank.

Vittas, Dimitri (2010): The Regulation of With-Profits and Unit-Linked Variable Payout Annuities. Mimeo. Financial and Private Sector. Washington, D.C.: The World Bank.

Vittas, Dimitri, Heinz Rudolph, and John Pollner (2010): Designing the Payout Phase of Funded Pension Pillars in Central and Eastern European Countries. Policy Research Working Paper No. 5276. Washington, D.C.: The World Bank.

Versicherungsaufsichtsgesetz in der Fassung der Bekanntmachung vom 17. Dezember 1992 (BGBl. 1993 I S. 2), zuletzt geändert durch Artikel 3 des Gesetzes vom 1. März 2011 (BGBl. I S. 288) geändert worden ist.

Wolfsdorf, K. (1997): Versicherungsmathematik, Teil 1, Stuttgart. 
Figure 1: Realized Net Investment Returns and Guaranteed Interest Rates (2004 - 2010)

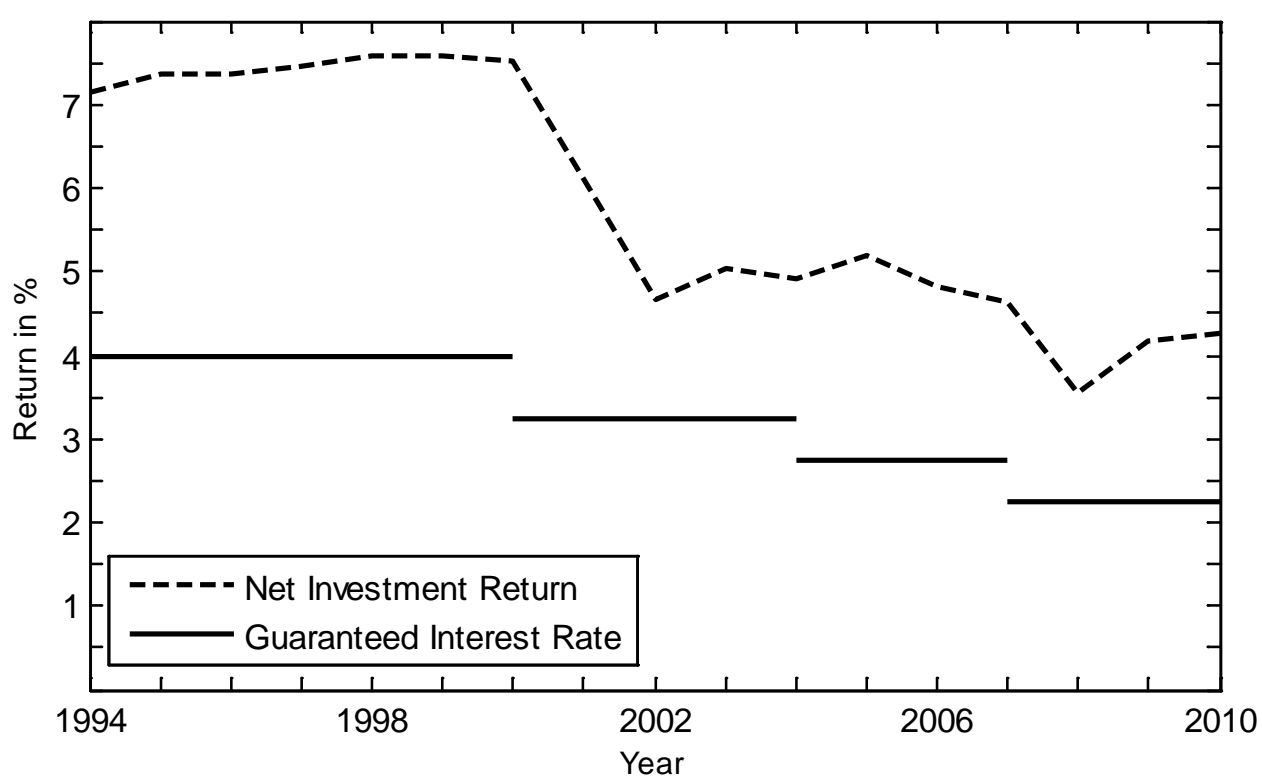

Notes: Average net investment return over all German Life Insurers. Maximum possible guaranteed interest rate according to premium refund order. Source: German Insurance Federation (GDV), Life insurance in numbers 2010.

Figure 2: Expected and Actual Mortality Rates

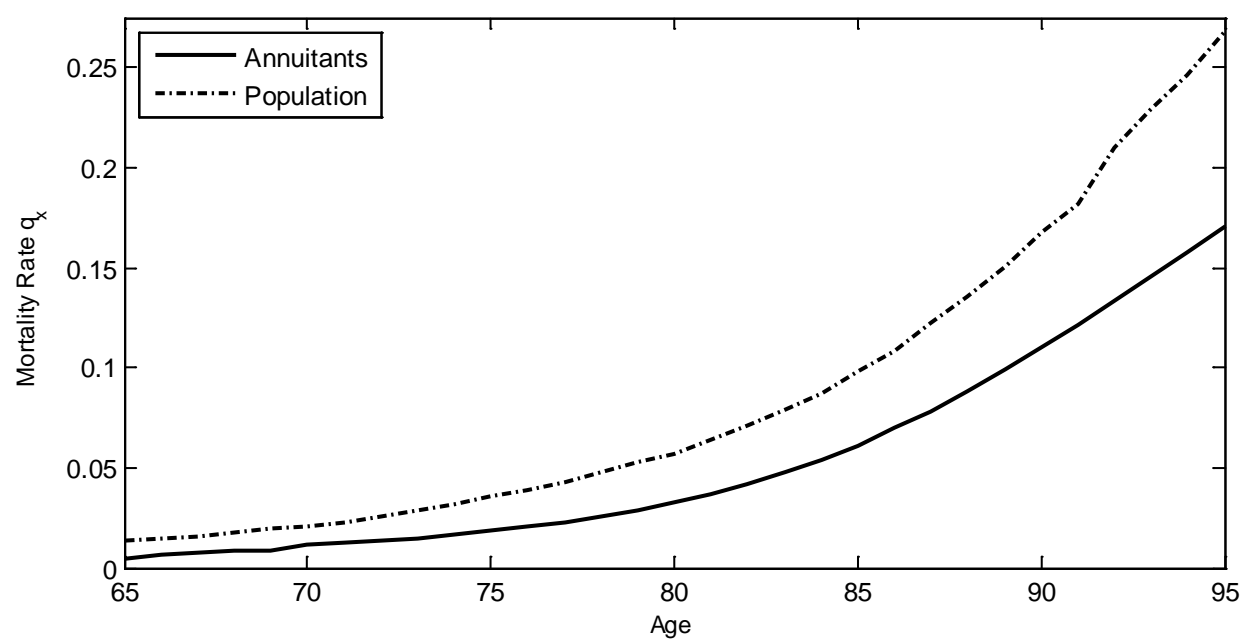

Notes: Mortality rates of a male born in 1946. German population as provided by Human Mortality Database, cohort table forecast by LC model. Annuitants' mortality and forecast as in mortality tables “DAV 2004 R”. Source: German Actuarial Society, Human Mortality Database. 
Figure 3: Process of Surplus Determination, Allocation, and Distribution

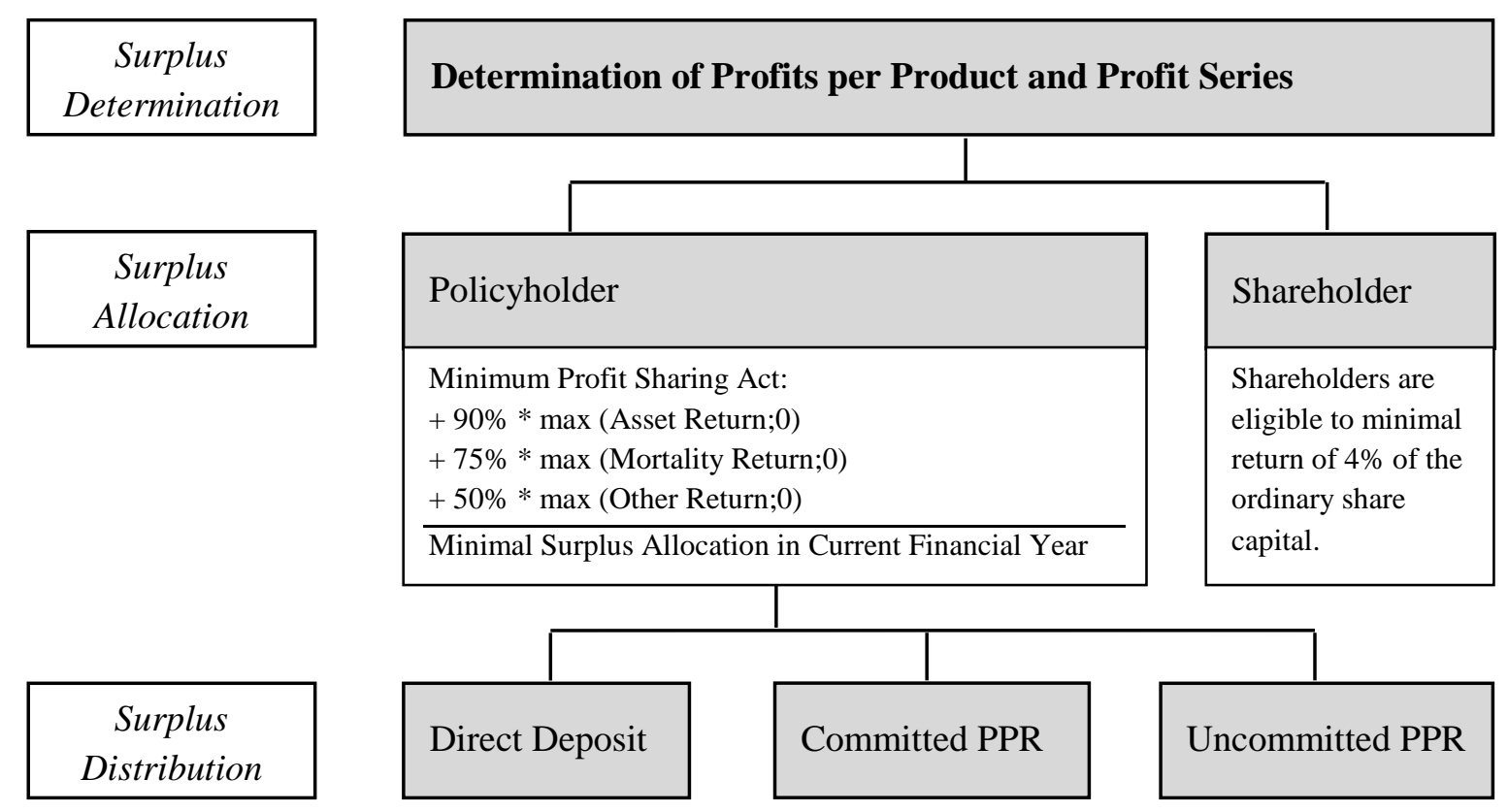

Source: Authors' Illustration. 
Figure 4: Development of Distributed Surpluses (2004 - 2010)

Panel 1: GIR 4.00\%, Mortality “DAV 1994 R”

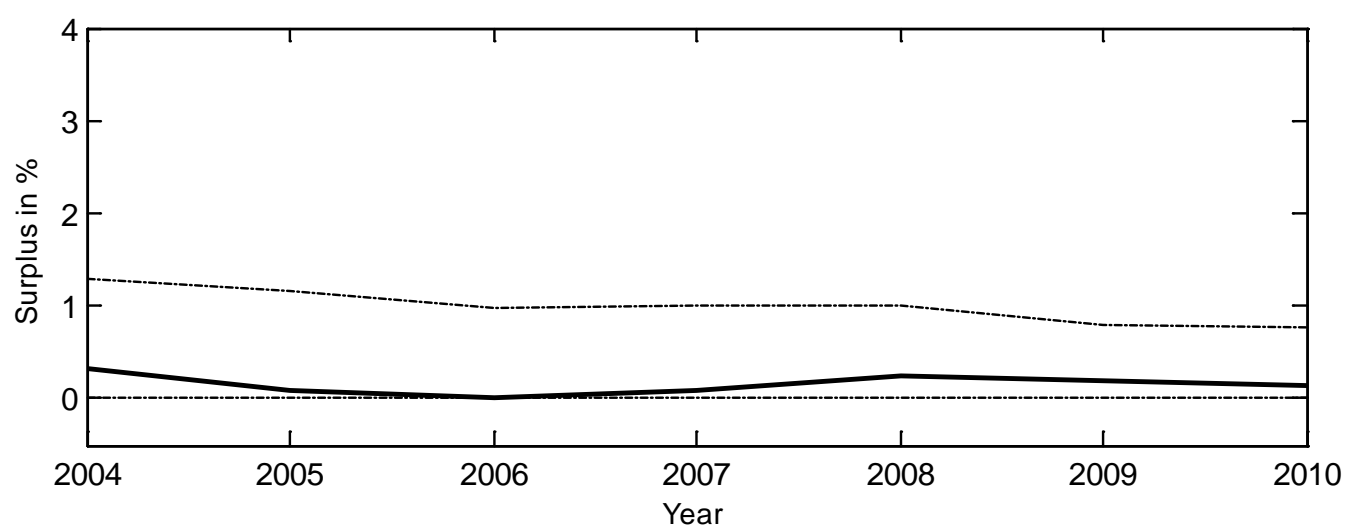

Panel 2: GIR 2.75\%, Mortality "DAV 2004 R"

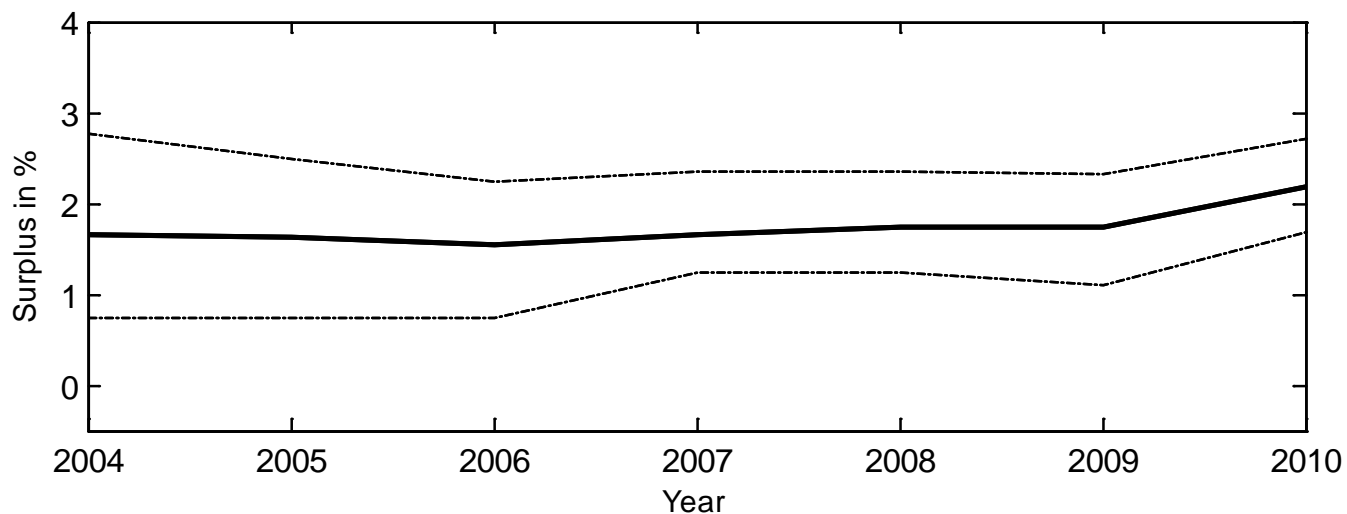

Notes: Range of Distributed Surpluses for different first order actuarial assumptions in percent of the actuarial reserve. Lower (upper) dash-dotted line represents the 5\% (95\%) quantile, solid line represent the average. Source: Assecurata Profit Sharing Studies 2004 to 2010, Authors' Illustration. 
Figure 5: Benefit Variation for Alternative Payout Schemes

Panel 1: Surplus Annuitization, GIR 4.00\%, “DAV 1994 R” Panel 2: Surplus Annuitization, GIR 2.75\%, “DAV 2004 R”
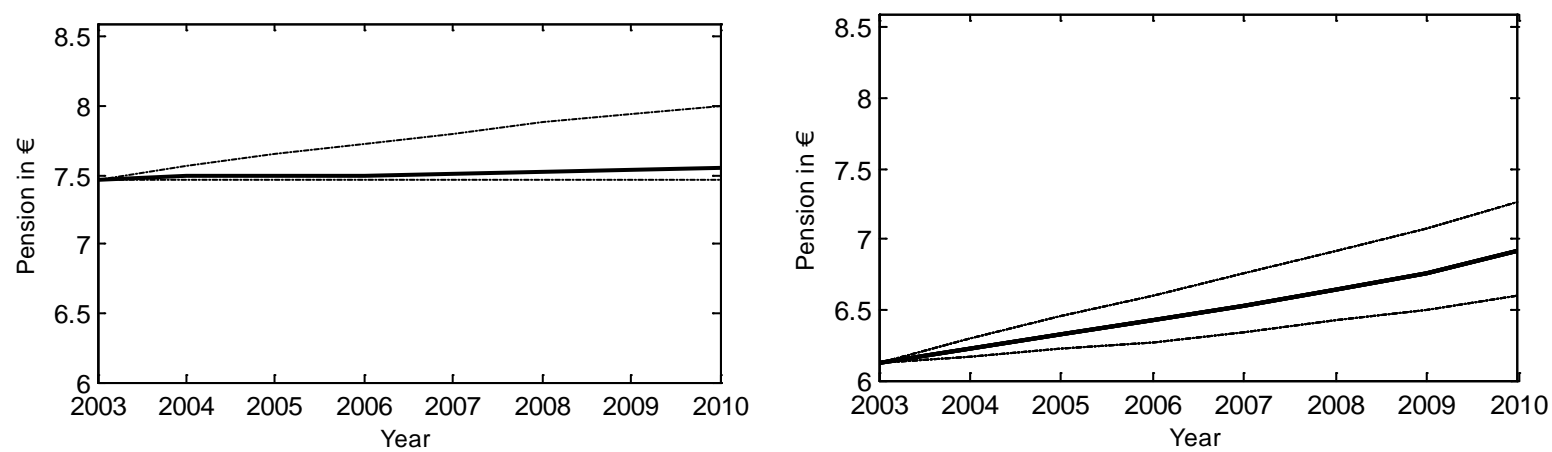

Panel 3: Surplus Lump-Sum, GIR 4.00\%, “DAV 1994 R”

Panel 4: Surplus Lump-Sum, GIR 2.75\%, “DAV 2004 R”
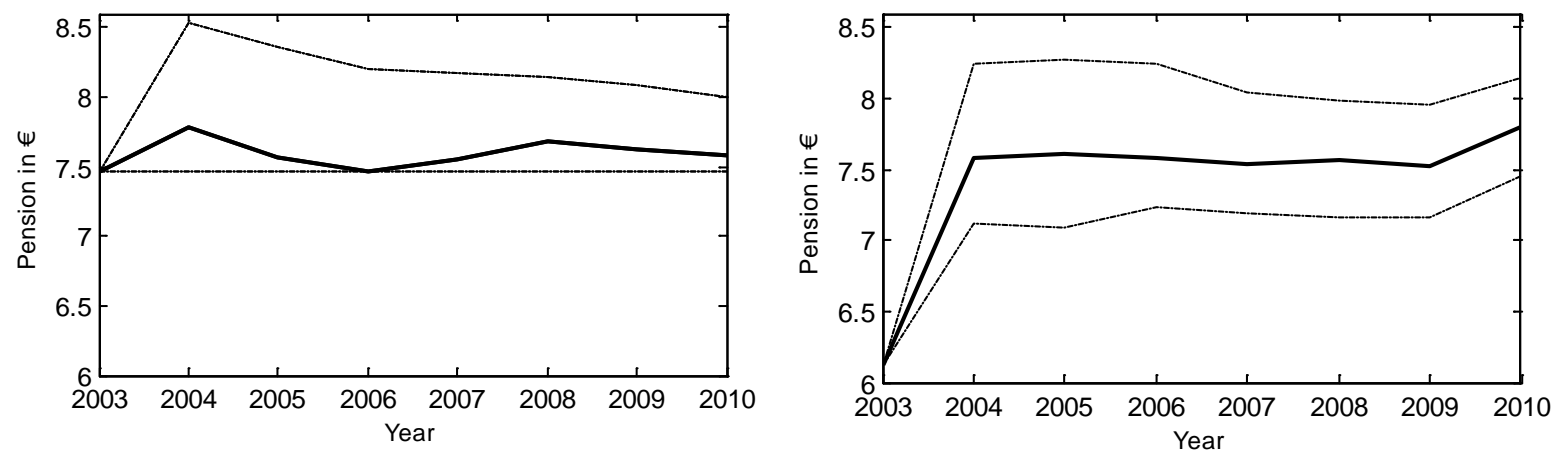

Notes: Range of the annual pension for different first order actuarial assumptions and surplus payout options. Male aged 65 in 2003. Initial investment of $100 €$. Lower (upper) dash-dotted line represents the 5\% (95\%) quantile, solid line represent the average. Source: Assecurata Profit Sharing Studies 2004 to 2010; Authors`calculations. 
Figure 6: Simulated Distributed Surplus, Annual Pension, and Equity Capital

Panel A: Base Case Scenario
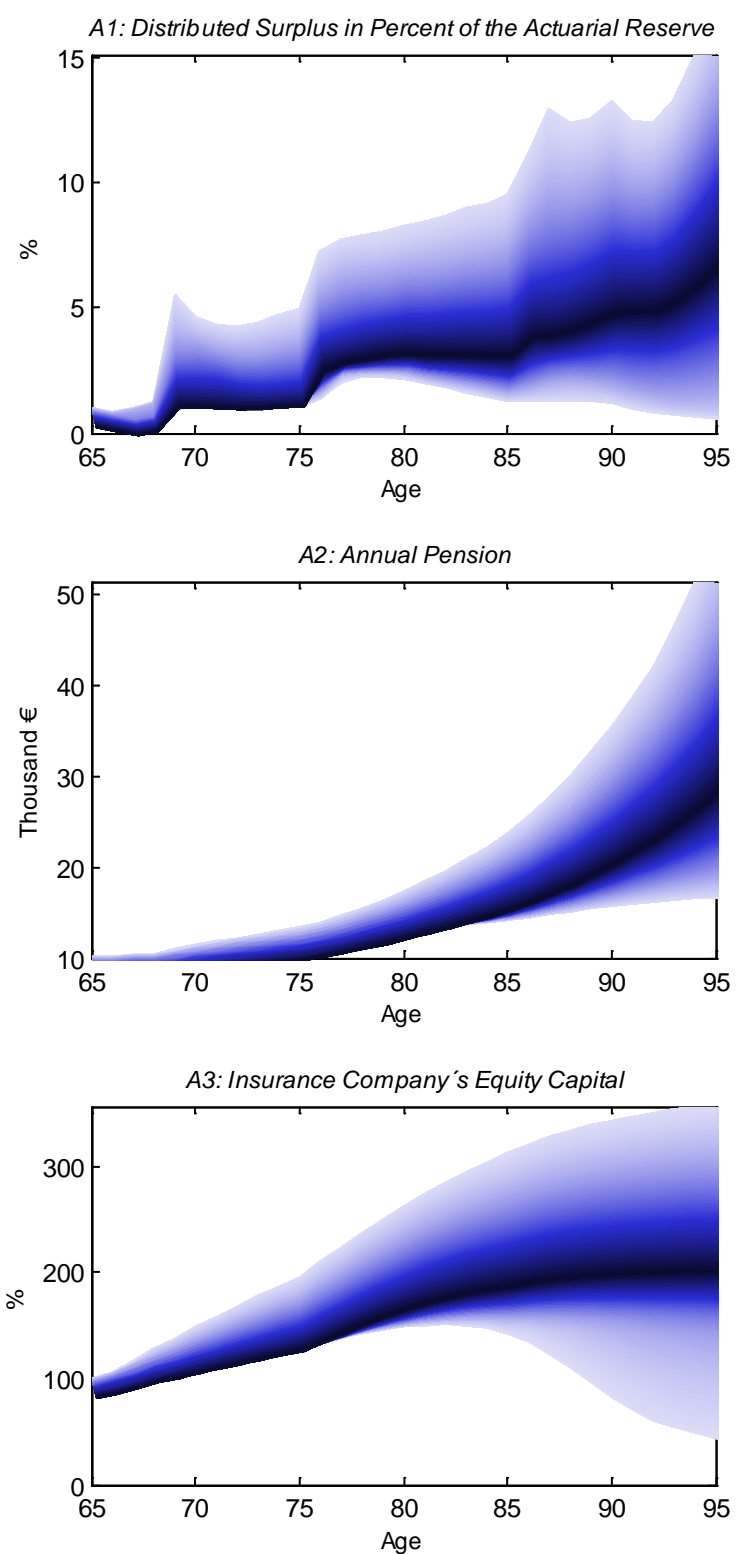

Panel B: Lump-Sum Scenario

B1: Distributed Surplus in Percent of the Actuarial Reserve

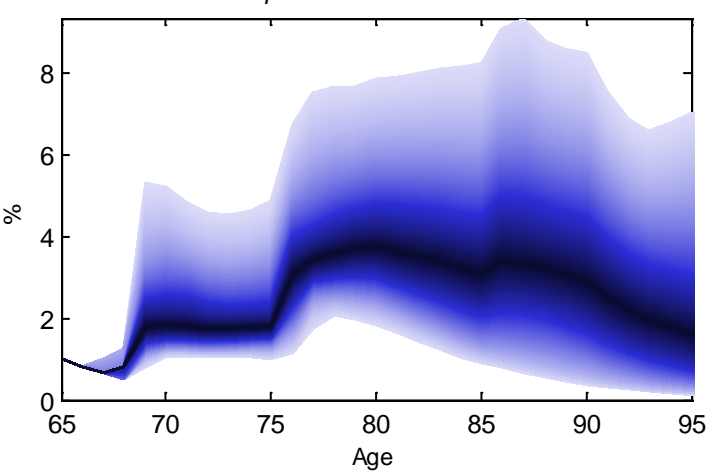

B2: Annual Pension

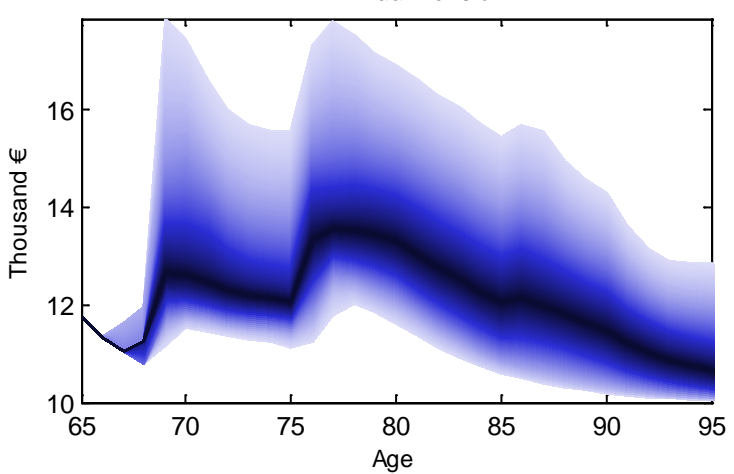

B3: Insurance Company's Equity Capital

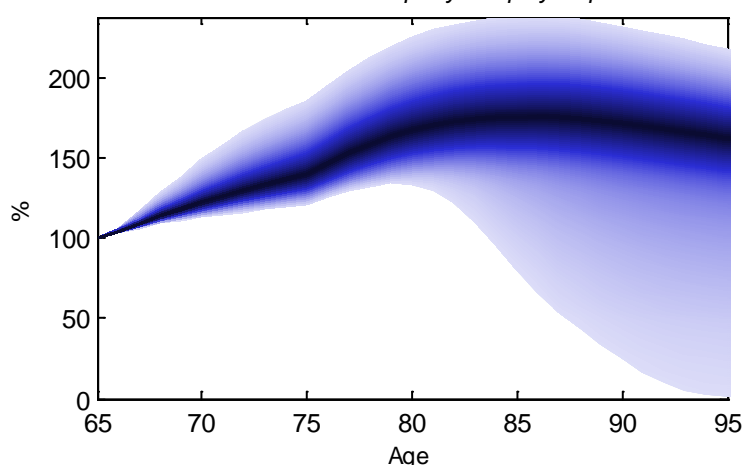

Notes: Simulated distribution of Distributed Surpluses, annual pension, and insurance company's equity capital (95\%:5\%) (50,000 simulations). Male aged 65 in 2012; initial guaranteed PLA pension 10,000€ (present value 178,196€); GIR 1.75\%; mortality "DAV 2004 R"; asset allocation 10\% stocks / 90\% bonds (with 10 years maturity); surplus allocation to annuitants: 92\%. Darker areas represent higher probability mass. Source: Authors`calculations. 
Figure 7: Money's Worth Ratio Distributions for Alternative Payout Schemes

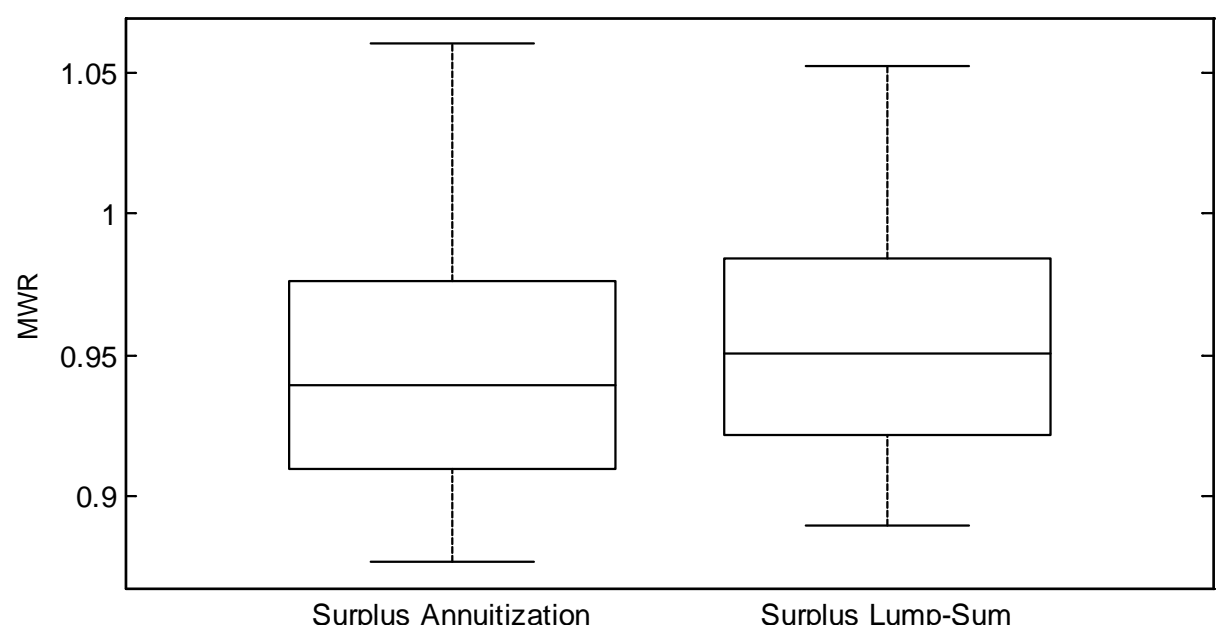

Notes: Range of the MWR for surplus annuitization and surplus lump-sum (50,000 simulations). Male aged 65 in 2012; initial guaranteed PLA pension 10.000€ (present value 178.196€); GIR 1.75\%; mortality "DAV 2004 R"; surplus annuitization / surplus lump-sum; asset allocation 10\% stocks / 90\% bonds (with 10 years maturity); surplus allocation 92\%. Lower (upper) whisker represents 5\% (95\%) MWR quantile, 25\%/50\%/75\% quantiles represented by the box. Source: Authors`calculations.

Figure 8: Money's Worth Ratio Distributions for Alternative Payout Schemes and Genders

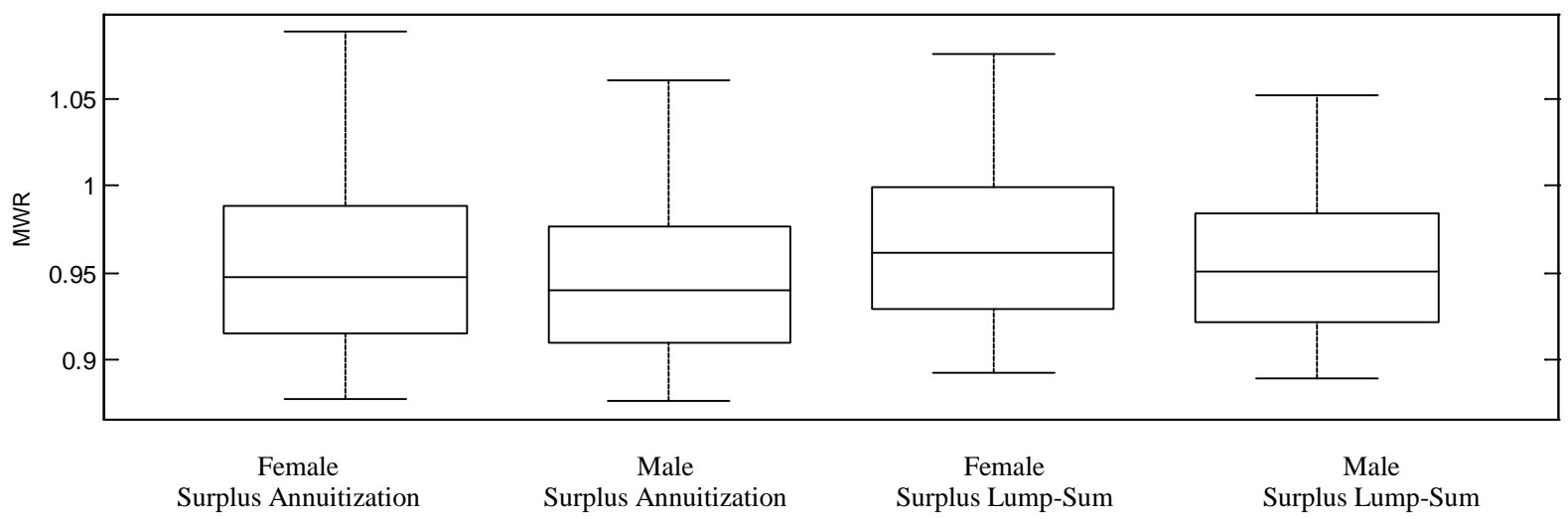

Notes: Range of the MWR of female and male for surplus annuitization and surplus lump-sum (50,000 simulations). Male / female aged 65 in 2012; initial guaranteed PLA pension 10,000€ (present value 198,828€ and 178,196€); GIR 1.75\%; mortality "DAV 2004 R"; asset allocation 10\% stocks / 90\% bonds (with 10 years maturity); surplus allocation to annuitants: 92\%. Lower (upper) whisker represents 5\% (95\%) MWR quantile, 25\%/50\%/75\% quantiles represented by the box. Source: Authors`calculations. 
Table 1: Surplus Analysis by Source of Return

\begin{tabular}{|c|c|c|c|c|c|c|}
\hline \multirow[b]{2}{*}{ Source of Return } & \multicolumn{2}{|r|}{2007} & \multicolumn{2}{|r|}{2008} & \multicolumn{2}{|r|}{2009} \\
\hline & in Million $€$ & in \% of Surplus & in Million $€$ & in \% of Surplus & in Million $€$ & in \% of Surplus \\
\hline Mortality & 6,352 & 46.2 & 6,489 & 95.3 & 6,464 & 54.7 \\
\hline Assets & 8,530 & 62.0 & 892 & 13.1 & 5,485 & 46.4 \\
\hline Costs & 913 & 6.6 & 771 & 11.3 & 1,147 & 9.7 \\
\hline Others & $-2,041$ & -14.8 & $-1,346$ & -19.8 & $-1,277$ & -10.8 \\
\hline Distributed Surplus & 13,754 & & 6,815 & & 11,819 & \\
\hline
\end{tabular}

Notes: Aggregated values over all product groups of all 101 (100/99) German Life Insurers in 2007 (2008/2009). Source: Federal Financial Supervisory Agency, Statistics for Direct Insurers 2009.

Table 2: Average Asset Allocation

\begin{tabular}{lr}
\hline Asset Class & Weight in \% \\
\hline Bonds & 66.5 \\
Investment Funds & 24.6 \\
Assets of Affiliated Companies & 2.9 \\
Properties & 1.5 \\
Direct Stocks Holdings & 0.6 \\
Others & 3.9 \\
\hline
\end{tabular}

Notes: Equally weighted asset allocation over all German Life Insurers in 2010. Source: Federal Financial Supervisory Agency, Statistics for Direct Insurers 2010.

Table 3: Realized Surpluses and Surplus Allocation (2005 - 2009)

\begin{tabular}{lrrrrr}
\hline & 2005 & 2006 & 2007 & 2008 & 2009 \\
\hline Surplus (in €bn) & 14.2 & 14.1 & 13.5 & 6.6 & 11.6 \\
Surplus Allocation (\%) & 92.9 & 92.6 & 92.6 & 86.9 & 90.0 \\
In Percent of the PPR & 2.6 & 2.5 & 2.3 & 1.1 & 1.9 \\
\hline
\end{tabular}

Notes: Aggregated values over all German Life Insurers. Source: Federal Financial Supervisory Agency, annual report 2009. 
Table 4: Average Distributed Surplus for Alternative Calibrations (in \%)

\begin{tabular}{cccccc}
\hline Age & Base Case & No Stocks & $\begin{array}{c}\text { Max. Stock } \\
\text { Fraction }\end{array}$ & $\begin{array}{c}\text { Short Bond } \\
\text { Maturity }\end{array}$ & $\begin{array}{c}\text { Regulatory } \\
\text { Min }\end{array}$ \\
\cline { 1 - 3 } 65 & 1.02 & 1.02 & 1.02 & 1.02 & 1.02 \\
70 & 1.82 & 1.52 & 2.15 & 0.97 & 1.51 \\
75 & 1.86 & 1.81 & 2.32 & 2.46 & 1.68 \\
80 & 3.97 & 3.61 & 4.71 & 3.49 & 3.38 \\
85 & 3.87 & 3.18 & 5.75 & 4.11 & 3.16 \\
90 & 5.57 & 4.37 & 9.01 & 5.18 & 4.33 \\
95 & 7.52 & 6.55 & 10.57 & 7.08 & 5.50 \\
\hline
\end{tabular}

Notes: Average Distributed Surplus in percent of the actuarial reserve at specified age. Base case assumptions: male aged 65 in 2012; initial guaranteed PLA pension 10,000€ (present value 178,196€); GIR 1.75\%; mortality "DAV 2004 R"; surplus annuitization; asset allocation $10 \%$ stocks / $90 \%$ bonds (with 10 years maturity); surplus allocation to annuitant: $92 \%$. No Stocks: asset allocation 0\% stocks / 100\% bonds. Max. Stock Fraction: asset allocation 30\% stocks / 70\% bonds. Short Bond Maturity: maturity of bonds 5 years. Regulatory Min: surplus allocation to annuitant: $90 \%$ asset returns, $75 \%$ mortality returns. Source: Authors`calculations.

Table 5: Utility-Equivalent Fixed Life Annuity (in € Thousands)

\begin{tabular}{|c|c|c|c|c|c|c|c|c|c|}
\hline \multirow{2}{*}{$\begin{array}{l}\text { Time Preference } \\
\text { Risk Aversion }\end{array}$} & \multicolumn{3}{|c|}{ Patient } & \multicolumn{3}{|c|}{ Normal } & \multicolumn{3}{|c|}{ Impatient } \\
\hline & Low & Medium & High & Low & Medium & High & Low & Medium & High \\
\hline Base Case & 12.08 & 11.78 & 11.53 & 11.53 & 11.34 & 11.17 & 11.12 & 10.99 & 10.89 \\
\hline Lump-Sum & 12.42 & 12.37 & 12.32 & 12.20 & 12.16 & 12.12 & 11.94 & 11.92 & 11.89 \\
\hline No Stocks & 12.03 & 11.72 & 11.45 & 11.49 & 11.29 & 11.11 & 11.09 & 10.96 & 10.85 \\
\hline Max Stock Fraction & 11.75 & 11.50 & 11.28 & 11.36 & 11.18 & 11.03 & 11.02 & 10.91 & 10.81 \\
\hline Short Bond Maturity & 12.34 & 12.00 & 11.70 & 11.59 & 11.39 & 11.22 & 11.13 & 11.00 & 10.90 \\
\hline Regulatory Min & 11.94 & 11.66 & 11.42 & 11.42 & 11.24 & 11.08 & 11.03 & 10.91 & 10.81 \\
\hline Female & 11.80 & 11.55 & 11.33 & 11.39 & 11.21 & 11.06 & 11.04 & 10.92 & 10.82 \\
\hline
\end{tabular}

Notes: Equivalent fixed life annuity (in $€$ thousands) that generates the same utility as a PLA with guaranteed initial pension of $10,000 €$ for alternative scenarios based on a time-additive CRRA utility function. Calibrations of time preference: $\beta=0.98$ (patient), $\beta=0.96$ (normal), $\beta=0.94$ (impatient); calibration of risk aversion: $\gamma=2$ (low), $\gamma=5$ (medium), $\gamma=10$ (high). Base case assumptions: male aged 65 in 2012; GIR 1.75\%; mortality "DAV 2004 R" (present value of PLA: $178,196 €$ ); surplus annuitization; asset allocation 10\% stocks / $90 \%$ bonds (with 10 years maturity); surplus allocation to annuitants: 92\%. Scenario (1) lump-sum annuitization; Scenario (2) asset allocation 0\% stocks / 100\% bonds; Scenario (3) asset allocation 30\% stocks / 70\% bonds; Scenario (4) maturity of bonds 5 years; Scenario (5) surplus allocation to annuitants: 90\% asset returns and 75\% mortality returns; Scenario (6) female age 65 in 2012. Source: Authors`calculations. 